\title{
Universiteit
}

Leiden

The Netherlands

\section{Eco-efficiency for greenhouse gas emissions mitigation of municipal solid waste management: a case study of Tianjin, China}

Zhao, W.; Huppes, G.; Voet, E. van der

\section{Citation}

Zhao, W., Huppes, G., \& Voet, E. van der. (2011). Eco-efficiency for greenhouse gas emissions mitigation of municipal solid waste management: a case study of Tianjin, China. Waste Management, 31(6), 1407-1415. doi:10.1016/j.wasman.2011.01.013

Version: Publisher's Version

License: $\quad$ Licensed under Article 25fa Copyright Act/Law (Amendment Taverne)

Downloaded from: https://hdl.handle.net/1887/3193756

Note: To cite this publication please use the final published version (if applicable). 


\title{
Eco-efficiency for greenhouse gas emissions mitigation of municipal solid waste management: A case study of Tianjin, China
}

\author{
Wei Zhao ${ }^{\mathrm{a}, \mathrm{b}, *}$, Gjalt Huppes ${ }^{\mathrm{b}}$, Ester van der Voet ${ }^{\mathrm{b}}$ \\ ${ }^{a}$ College of Civil Engineering E Architecture, Liaoning University of Technology, 121000 Jinzhou, China \\ ${ }^{\mathrm{b}}$ Institute of Environmental Sciences (CML), Leiden University, P.O. Box 9518, 2300RA Leiden, The Netherlands
}

\section{A R T I C L E I N F O}

\section{Article history:}

Received 9 April 2010

Accepted 7 January 2011

Available online 12 February 2011

\begin{abstract}
A B S T R A C T
The issue of municipal solid waste (MSW) management has been highlighted in China due to the continually increasing MSW volumes being generated and the limited capacity of waste treatment facilities. This article presents a quantitative eco-efficiency (E/E) analysis on MSW management in terms of greenhouse gas (GHG) mitigation. A methodology for $\mathrm{E} / \mathrm{E}$ analysis has been proposed, with an emphasis on the consistent integration of life cycle assessment (LCA) and life cycle costing (LCC). The environmental and economic impacts derived from LCA and LCC have been normalized and defined as a quantitative E/E indicator. The proposed method was applied in a case study of Tianjin, China. The study assessed the current MSW management system, as well as a set of alternative scenarios, to investigate trade-offs between economy and GHG emissions mitigation. Additionally, contribution analysis was conducted on both LCA and LCC to identify key issues driving environmental and economic impacts. The results show that the current Tianjin's MSW management system emits the highest GHG and costs the least, whereas the situation reverses in the integrated scenario. The key issues identified by the contribution analysis show no linear relationship between the global warming impact and the cost impact in MSW management system. The landfill gas utilization scenario is indicated as a potential optimum scenario by the proposed $\mathrm{E} / \mathrm{E}$ analysis, given the characteristics of MSW, technology levels, and chosen methodologies. The E/E analysis provides an attractive direction towards sustainable waste management, though some questions with respect to uncertainty need to be discussed further.
\end{abstract}

(c) 2011 Elsevier Ltd. All rights reserved.

\section{Introduction}

In the context of sustainable waste management, strategies are decided by concerns for the three pillars of sustainability: environment, economy and society. Based on this concept, two types of methods have been developed to support decision making processes in the area of waste management: cost benefit analysis (CBA) (Eshet et al., 2005; Ibenholt and Lindhjem, 2003; RDC and PIRA, 2003), and eco-efficiency (E/E) analysis (Hellweg et al., 2005; Indrianti et al., 2007) derived from life cycle approaches. Additionally, some studies (Reich, 2005) have employed an environmental life cycle costing (ELCC) method, which internalized and included the external environmental burdens into the total cost. Although ELCC has been developed based on life cycle approaches as well, it can be similar to CBA. It is critical to clarify the inherent differences between these two types of methods,

\footnotetext{
* Corresponding author at: College of Civil Engineering \& Architecture, Liaoning University of Technology, Shiying Road 169, Guta District, 121000 Jinzhou, China. Tel.: +86 416 4199697; fax: +86 4163988299.

E-mail addresses: zhaowei.tju@gmail.com (W. Zhao), huppes@cml.leidenuniv.n (G. Huppes), Voet@cml.leidenuniv.nl (E. van der Voet).
}

before using these methods to reflect and understand reality. Considering the economic and environmental pillars in sustainability, the principle of CBA is achieving maximum social welfare, by assuming that environmental impacts can be valued as economic costs or benefits; whereas the principle of $\mathrm{E} / \mathrm{E}$ analysis is creating economic value while decreasing environmental burdens. CBA has been often conducted on the project level and employs a discounting approach to aggregating the results. Compared to CBA, $\mathrm{E} / \mathrm{E}$ analysis is superior in optimizing the decision. For instance, an alternative with environmental improvements at lower cost, which is always preferable, can be distinguished by the E/E analysis; whereas, the results of the CBA analysis, subject to no consensus on how to monetize environmental impacts, may indicate different preferences. Therefore, by softly linking the absolute domain of environmentalism and the subjective domain of economic welfare, the $\mathrm{E} / \mathrm{E}$ analysis presents a more modest way to consider the trade-offs between both aspects, as concluded by Huppes and Ishikawa (2005a).

The importance of the waste sector for reducing global greenhouse gas (GHG) emissions has gained considerable attention, and widespread efforts have been made to promote the evaluation of GHG emissions from the waste sector, especially since waste 
management as a new chapter was included in the IPCC's Fourth Assessment Report (Bogner et al., 2007). China is a meaningful case for this global issue, because of its continually increasing MSW generation, which has been estimated to show an average annual growth rate of $8-10 \%$ (Cheng et al., 2007). The decisions on GHG emissions mitigation need to be evaluated based on Chinese MSW management practices. Additionally, given the limited financial support, decisions should be directly related to economic cost or value. Against the above background, the $\mathrm{E} / \mathrm{E}$ analysis is an attractive tool for this topic. However, little research has been done on the $\mathrm{E} / \mathrm{E}$ analysis for greenhouse gas emissions mitigation of MSW.

The remainder of this article is structured as follows: a methodology section discusses the consistency of life cycle assessment (LCA) and life cycle costing (LCC), for implementing the E/E analysis without conflicts. Further, an E/E indicator is developed to evaluate strategies on GHG emissions mitigation in MSW management system. The subsequent case study section presents a quantitative and illustrative example of the proposed E/E analysis for GHG emissions mitigation of Tianjin's MSW management, including six scenarios which reflect the current and possible patterns of MSW management system. Moreover, a contribution analysis is used to highlight the key issues in different scenarios, with regard to both environmental and economic aspects. Finally, the conclusions section summarizes the results and discusses several practical issues and limitations arising in this study.

\section{Methodology}

$\mathrm{E} / \mathrm{E}$, as a general concept initially introduced by the World Business Council on Sustainable Development (WBCSD, 2000), has been adopted in industrial practices. The E/E analysis provides the integrated information of the economic value and the environmental consequences of strategies, hence closely connected LCA (Guinée et al., 2002) and LCC (Huppes et al., 2004). LCA evaluates the environmental impacts of a product or service induced throughout its life cycle, whereas LCC evaluates the total cost for realizing the same function. The results of both analyses are exactly the elements of $\mathrm{E} / \mathrm{E}$ analysis. Though the concept of $\mathrm{E} / \mathrm{E}$ itself is not complicated and life cycle analytical tools have been well developed, it is critical to clarify the differences between LCA and LCC methodologies, in order to carry out the E/E analysis in a consistent way. Furthermore, an $\mathrm{E} / \mathrm{E}$ indicator needs to be defined for this case study, aiming to quantify the $\mathrm{E} / \mathrm{E}$ as one figure.

\subsection{Consistency of LCA and LCC}

LCA and LCC have major methodological differences inherently, which are classified based on their relevance to the time or the boundary, as summarized in Table 1 . These methodological differences stem from the fact that LCA and LCC have been established in different domains with different purposes. When we consider these differences, it seems difficult, if not even conflicting, to directly integrate the results of LCA and LCC in the E/E analysis. For consistent reason, the choice needs to be made between two approaches: either to adapt LCA methodology to LCC methodology, or to adapt LCC methodology to LCA methodology.

From the time related view, Huppes et al. (2004) have discussed this choice, and key conclusions are: (1) a steady-state type of LCC can conceptually best be linked to a steady-state LCA; (2) various discount rates may lead to diverging outcomes, and the real cost without discounting, as a simple assumption, is preferred. From the boundary related view, allocation is the most critical issue in life cycle analytical tools, due to its essential influence on outcomes. Heijungs and Guinée (2007) have analyzed the logical as well as practical problems when carrying out both economic allocation and substitution procedures in LCA studies. When performing the $\mathrm{E} / \mathrm{E}$ analysis, there is no doubt that a consistent allocation method needs to be applied in both LCA and LCC. The choice between economic allocation and substitution becomes more explicit and also more straightforward in the case of the E/E analysis. From a theoretical point of view, it is reasonable that the economic allocation solves the problems related to multi-functional processes in an economic analysis; from a practical point of view, when the economic allocation is employed, LCA and LCC share the same allocation factors and extra information on costs of substitute processes is not necessary. It is noted that several LCC studies have solved the multi-functional problem by a substitution approach. That means the revenues of co-products are subtracted from the total costs; thus the net costs are considered as the functional unit bore cost. A closer look at allocation based on subtracted revenues shows an underlying assumption, namely, that the market price of the co-product is equal to the cost of the co-product. The choice of unit processes is the other difference between LCA and LCC. Although the same set of unit processes can be inventoried in both LCA and LCC in principle, it is a consensus of researchers that if a detailed assessment of all single unit process is unavailable, the market price of a given economic inflow or outflow is considered as the aggregated upstream costs or downstream costs.

As aforementioned, making the choice of LCC and LCA methodologies in the E/E analysis is a delicate subject. Summarily, in order to avoid the logical conflicts and perform the $\mathrm{E} / \mathrm{E}$ analysis in a practical way, key choices of methodological issues in this study are as follows:

- the steady-state LCC model is used, aligning to LCA;

- the standard LCA methodology is followed, as described by Guinée et al. (2002);

Table 1

Methodological differences between LCA and LCC.

\begin{tabular}{|c|c|c|}
\hline & LCA & LCC \\
\hline \multicolumn{3}{|c|}{ Time related differences } \\
\hline Model feature & $\begin{array}{l}\text { Most LCAs use a steady-state model, } \\
\text { ignoring the time specification }\end{array}$ & $\begin{array}{l}\text { Most LCCs use a quasi-dynamic model; and } \\
\text { some use a steady-state model }\end{array}$ \\
\hline Time horizon & $\begin{array}{l}\text { Some environmental impacts are time independent; } \\
\text { some address a fixed time horizon (e.g. global } \\
\text { warming potential for } 100 \text { years) }\end{array}$ & $\begin{array}{l}\text { Cost impact covers the main stages of service, including design, } \\
\text { construction, use and disposal. Traditionally LCC's time span } \\
\text { is shorter than that in LCA }\end{array}$ \\
\hline Aggregation & $\begin{array}{l}\text { Future environmental impacts are generally } \\
\text { not discounted in the results }\end{array}$ & $\begin{array}{l}\text { Most LCCs use discount rates to aggregate different costs; } \\
\text { some exclude discounting }\end{array}$ \\
\hline \multicolumn{3}{|c|}{ Boundary related differences } \\
\hline Allocation & $\begin{array}{l}\text { Substitution with the expanded system boundary or different } \\
\text { options for allocation (e.g. economic, energy, mass) }\end{array}$ & $\begin{array}{l}\text { Substitution with the expanded system boundary or } \\
\text { economic allocation or revenues included (e.g. net cost) }\end{array}$ \\
\hline System & $\begin{array}{l}\text { From cradle to grave, all relevant unit processes are } \\
\text { involved if possible }\end{array}$ & $\begin{array}{l}\text { Main unit processes are involved, and other upstream or downstream } \\
\text { processes are covered by assuming their costs are their market prices }\end{array}$ \\
\hline
\end{tabular}


- ignoring the time specification, LCC is presented as an average yearly cost without discounting;

- economic allocation is applied in both LCA and LCC.

\subsection{Eco-efficiency indicator}

$\mathrm{E} / \mathrm{E}$ is primarily described as a strategy that creates more value with less ecological impact and used in production systems. When we are extending the $\mathrm{E} / \mathrm{E}$ analysis to waste management, the situation becomes more difficult and complicated, since many participants are involved in the waste management system and the analysis based on an individual firm level is restricted. In the area of waste management, the $\mathrm{E} / \mathrm{E}$ is analyzed on the functional level, referring to the same functional unit in both LCA and LCC, viz. the disposal of a given amount of MSW. This functional unit can be provided by different processes with different LCA and LCC scores. In this article, we consider reducing GHG emissions from the MSW management system. Thus the question arises as to which strategy, involving which treatment process is the most eco-efficient.

For calculating E/E, we assess the global warming impact and cost impact of each process included in different scenario, with assistance of LCA and LCC. For the $i$ th MSW management scenario, its global warming impact $G W$ (measured in ton $\mathrm{CO}_{2}$ eq.) and cost impact $C$ (measured in Chinese Yuan, $C N Y$ ) are defined as:

$$
\begin{aligned}
& G W_{i}=\sum_{k} G W_{i}^{k} \\
& C_{i}=\sum_{k} C_{i}^{k}
\end{aligned}
$$

where superscript $k$ denotes the $k$ th waste treatment process.

When the environmental and economic assessments are ready, there are three ways to represent E/E: internal normalization relative to the current situation or the average situation, external normalization relative to the national level or the global level, and actual value without normalization. Limitations of the internal normalization have been discussed by Huppes and Ishikawa (2005b), e.g. leading to diverse results, dependence on irrelevant alternatives, or difficulties in cross-case comparisons. The external normalization has advantages in independence and estimating the distance to a specific target, which is the case that under the Kyoto Protocol and the EU Burden-Sharing Agreement, The Netherlands' GHG emissions are expected to reduce $6 \%$ by 2010 , compared to the base-year. In order to bring LCA and LCC scores in a comparable line, this study uses the external normalization of LCA and LCC, which sets the specific scores into relation to a national level. Accordingly, the normalized global warming $(N G W)$ and the normalized cost $(N C)$ are:

$$
\begin{aligned}
& N G W_{i}=G W_{i} / G N E I \\
& N C_{i}=C_{i} / G D P
\end{aligned}
$$

where GNEI is the gross national environmental impact of global warming of the base-year, ton $\mathrm{CO}_{2}$ eq./year; GDP is the gross domestic product of a certain year, $\mathrm{CNY} /$ year.

An $E / E_{\text {pairwise }}$ indicator (Huppes and Ishikawa, 2005b), is applied in this study, in order to combine the environmental impact difference and the cost difference between any two scenarios. Since the present study focuses on evaluating strategies for GHG emissions mitigation of MSW management system, $E / E_{\text {pairwise }}$ is redefined as:

$$
E / E_{\text {pairwise }, i j}= \begin{cases}\left(N G W_{j}-N G W_{i}\right) /\left(N C_{i}-N C_{j}\right) & N G W_{j}>N G W_{i}, N C_{i}>N C_{j} \\ \rightarrow \infty & N G W_{j}>N G W_{i}, N C_{i} \leqslant N C_{j} \\ n / a & N G W_{j} \leqslant N G W_{i}\end{cases}
$$

If $N G W_{j}>N G W_{i}$ and $N C_{i}>N C_{i}$, which means scenario $i$ is better in terms of global warming impact but costs more than scenario $j, E / E_{\text {pairwise, } i j}$ illustrates GHG emissions mitigation per unit cost by shifting from scenario $j$ to scenario $i$. If $N G W_{j}>N G W_{i}$ and $N C_{i} \leqslant N C_{i}$, which means scenario $i$ is better than scenario $j$ in terms of both global warming and cost impacts, no cost is needed to achieve GHG emissions mitigation by shifting from scenario $j$ to scenario $i$ in other words, $E / E_{\text {pairwise } i j}$ approaches infinity. If $N G W_{j} \leqslant N G W_{i}$, it makes no sense for GHG emissions mitigation by shifting from scenario $j$ to scenario $i$; therefore $E / E_{\text {pairwise, } i j}$ is not available. This expression of the proposed $E / E_{\text {pairwise, } i j}$ indicator holds the common meaning of efficiency, viz. higher is better.

\section{Case study of Tianjin}

The E/E analysis for GHG emissions mitigation of MSW was implemented in Tianjin, one of the four municipalities directly under the Central Government, with an urban area of $11,920 \mathrm{~km}^{2}$ and 10.75 million inhabitants. Tianjin's GDP has grown by an annual $13.9 \%$ over the past 5 years, and the annual per capital GDP was 40,350 CNY in 2006 (TBS, 2007), the fifth highest in China. MSW is being generated at a rate of approximately 4500 tons per day and $85 \%$ is collected and treated legally. Landfill is the main disposal approach in Tianjin's MSW management system, complemented by incineration.

\subsection{Goal and scope definition}

The goal of this study is twofold: to evaluate $E / E$ of the existing MSW management in Tianjin from a GHG emissions perspective; and to investigate $\mathrm{E} / \mathrm{E}$ of strategies for GHG emissions mitigation of MSW management.

\subsubsection{Functional unit}

The functional unit is defined as "the disposal of the MSW collected from the central districts of Tianjin city in 2006". The total amount is 909,160 tons. MSW refers to the waste discarded in the urban areas. This is mainly household and retailer waste, but also includes small amounts of industrial and construction wastes mixed in occasionally. The fraction composition and elementary composition of MSW has been analyzed (TCAEEDRI, 2007), as shown in Table 2.

\subsubsection{Scenarios}

Six scenarios, reflecting different MSW management systems, are compared in this study. The scenarios are assumed not to influence MSW generation; hence the same amounts of MSW with the same composition are disposed in all scenarios.

- SO Baseline: The S0 corresponds to the current MSW management system in the central district of Tianjin. Landfill without landfill gas (LFG) utilization is the main disposal approach, with the complement of incineration. The average electricity generation efficiency of MSW-to-energy is $23.85 \%$, which bases on the lower heating value of MSW (Tianjin MSW-to-energy plant, 2006).

- S1 LFG utilization: S1 is constructed to evaluate the strategy of landfill with LFG utilization. In comparing to S0, LFG collection, upgrade, and conversion system are equipped for landfill plant in this scenario. The LFG collection efficiency is 50\%. LFG is assumed to produce electricity.

- S2 Incineration: All of the MSW is treated in the MSW-to-energy plant. This scenario tests the benefit from incineration with energy recovery instead of landfill.

- S3 Material recycling: In comparing to S0, mixed metals, glass, paper, and plastics are assumed to be treated in a material recycle facility (MRF) in S3, producing secondary materials. The secondary materials are assumed to the replace virgin 
Table 2

Fraction composition and elementary composition of MSW in Tianjin.

\begin{tabular}{|c|c|c|c|c|c|c|c|c|}
\hline Fraction & Fraction (\%) & Moisture (\%) & C (\%) & $\mathrm{H}(\%)$ & $\mathrm{O}(\%)$ & $\mathrm{N}(\%)$ & $\mathrm{S}(\%)$ & Ash (\%) \\
\hline Kitchen waste & 56.9 & 70 & $48(100)^{a}$ & 6.4 & 37.6 & 2.6 & 0.4 & 5 \\
\hline Slag\&ceramics & 16.2 & 20 & $24.3(0)$ & 3 & 4 & 0.5 & 0.2 & 68 \\
\hline Metals & 0.4 & 2 & $4.5(0)$ & 0.6 & 4.3 & 0.1 & 0 & 90.5 \\
\hline Glass & 1.3 & 2 & $0.5(0)$ & 0.1 & 0.4 & 0.1 & 0 & 98.9 \\
\hline Paper & 8.7 & 10.2 & $43.4(100)$ & 5.8 & 44.3 & 0.3 & 0.2 & 6 \\
\hline Plastics & 12.1 & 1.2 & $60(0)$ & 7.2 & 22.8 & 0 & 0 & 10 \\
\hline Textiles & 2.5 & 10 & $48(80)$ & 6.4 & 40 & 2.2 & 0.2 & 3.2 \\
\hline Wood & 1.9 & 1.3 & $49.6(100)$ & 6 & 42.6 & 0.2 & 0.1 & 1.5 \\
\hline Total/average & 100 & 44.4 & $44.5(64)$ & 5.7 & 30.7 & 1.6 & 0.2 & 17.3 \\
\hline
\end{tabular}

a The percentage of biogenic carbon in the MSW is bracketed. Elementary composition of MSW is analyzed based on dry weight.

materials. Since the scavenging activities exist in nearly every stage of Tianjin's MSW management, relatively small amount of materials goes to MRF, as shown in Table 3. In the absence of data on recycling for mixed waste, a simplified recycle rate of $30 \%$ is assumed from average data recommend by U.S.EPA (Thorneloe et al., 2007). This rate is applied to all recyclable materials. Landfill without LFG utilization is the destination of residues of MRF.

- S4 Centralized composting: The design of this scenario is based on Tianjin's waste management proposal. Fifty percent of kitchen waste is assumed to be separated at the source and collected to be composted. The digested matter is used as soil conditioner or fertilizer. Landfill without LFG utilization is the destination of residues of composting. The same amount of MSW with the same composition as S0 is send to MSW-toenergy plant. The remaining MSW is assumed to be landfilled without LFG utilization.

- S5 Integrated system: This scenario investigates an integrated MSW management system, which takes advantage of all above scenarios. MRF and composting are the same as processes in S3 and S4. The same amount of MSW as S0 is sent to the MSW-toenergy plant. The remaining is treated in landfill with LFG utilization.

Table 3 shows the numbers of waste treatment facilities and the amounts of MSW inflow for each scenario. The number of plants is calculated based on the typical capacities of the Tianjin landfill plant and incineration plant.

\subsubsection{System boundary}

Different from products system, decisions on strategies for MSW management are often taken at the municipal level. The system boundary of this study is shown in Fig. 1. There are two types of processes, together composing the whole life cycle of MSW treatment, within the system boundary. One type is MSW treatment processes, including various waste treatment technologies and their downstream processes. The other type is upstream pro- cesses, providing ancillary materials and energy for waste treatment processes. Based on the processes in the life cycle of MSW treatment, three kinds of actors are involved in MSW management system: municipality, inhabitants and service providers. Monetary flows, as shown with dashed lines in Fig. 1, include the disposal fee collected from inhabitants, subsidies and taxes between municipality and service providers, costs and revenues directly generated between service providers and MSW management system. The disposal fee, taxes and subsidies are transfer payments between different actors; hence these monetary flows can be ignored.

\subsection{Environmental assessment with LCA and economic assessment with LCC}

\subsubsection{Key assumptions}

- Short-cycle biogenic $\mathrm{CO}_{2}$ emission is considered to be carbonneutral, in order to make results comparable with other studies. Biogenic carbon released as $\mathrm{CH}_{4}$, however, is included. The benefits of the biogenic carbon sink in the landfill process are not taken into account.

- The MSW-to-energy plant and landfill plant are located at the edge of the central district of Tianjin city. The collection and transport distance to MSW-to-energy plant and landfill plant is assumed as an average of $20 \mathrm{~km}$. The MRF and composting plant are assumed to be constructed in the periphery of the central district, with a collection and transport distance of $30 \mathrm{~km}$.

- The emissions of $\mathrm{CO}_{2}, \mathrm{~N}_{2} \mathrm{O}$, and $\mathrm{CH}_{4}$ from MSW management system are included in the LCA impact assessment, as the major contributors to global warming.

- Market prices for purchase of materials and energy are assumed to include all cost in supply chains, and exclude value added tax.

\subsubsection{Data issues}

The data sources for the life cycle inventory of each treatment process are listed in Table 4, for further descriptions see Zhao et al. (2009). Three cost categories are distinguished: capital costs,

Table 3

Number of facilities and MSW inflow data in different scenarios.

\begin{tabular}{|c|c|c|c|c|c|c|c|c|c|c|c|}
\hline \multirow[t]{3}{*}{ Scenario } & \multicolumn{11}{|c|}{ Waste treatment facility } \\
\hline & \multicolumn{2}{|c|}{$\begin{array}{l}\text { Landfill without LFG } \\
\text { utilization }\end{array}$} & \multicolumn{2}{|c|}{$\begin{array}{l}\text { Landfill with LFG } \\
\text { utilization }\end{array}$} & \multicolumn{2}{|c|}{ MSW-to-energy } & \multicolumn{2}{|l|}{ MRF } & \multicolumn{2}{|c|}{ Composting } & \multirow{2}{*}{$\begin{array}{l}\text { Open dumped } \\
\text { MSW inflow/ } \\
\text { ton }\end{array}$} \\
\hline & Number & $\begin{array}{l}\text { MSW inflow/ } \\
\text { ton }\end{array}$ & Number & $\begin{array}{l}\text { MSW inflow/ } \\
\text { ton }\end{array}$ & Number & $\begin{array}{l}\text { MSW inflow/ } \\
\text { ton }\end{array}$ & Number & $\begin{array}{l}\text { MSW inflow/ } \\
\text { ton }\end{array}$ & Number & $\begin{array}{l}\text { MSW inflow/ } \\
\text { ton }\end{array}$ & \\
\hline So & 1 & 450,000 & 0 & 0 & 1 & 438,000 & 0 & 0 & 0 & 0 & 21,160 \\
\hline $\mathrm{S} 1$ & 0 & 0 & 1 & 471,160 & 1 & 438,000 & 0 & 0 & 0 & 0 & 0 \\
\hline $\mathrm{S} 2$ & 0 & 0 & 0 & 0 & 2 & 909,160 & 0 & 0 & 0 & 0 & 0 \\
\hline S3 & 1 & 409,765 & 0 & 0 & 1 & 438,000 & 1 & 61,395 & 0 & 0 & 0 \\
\hline S4 & $0.5^{\mathrm{a}}$ & 212,595 & 0 & 0 & 1 & 438,000 & 0 & 0 & 1 & 258,565 & 0 \\
\hline S5 & 0 & 0 & $0.5^{a}$ & 151,200 & 1 & 438,000 & 1 & 61,395 & 1 & 258,565 & 0 \\
\hline
\end{tabular}

\footnotetext{
a An assumption in S4 and S5 is that half landfill plant is required, since the MSW inflow of landfill is around 50\% of the capacity of existing landfill plant.
} 


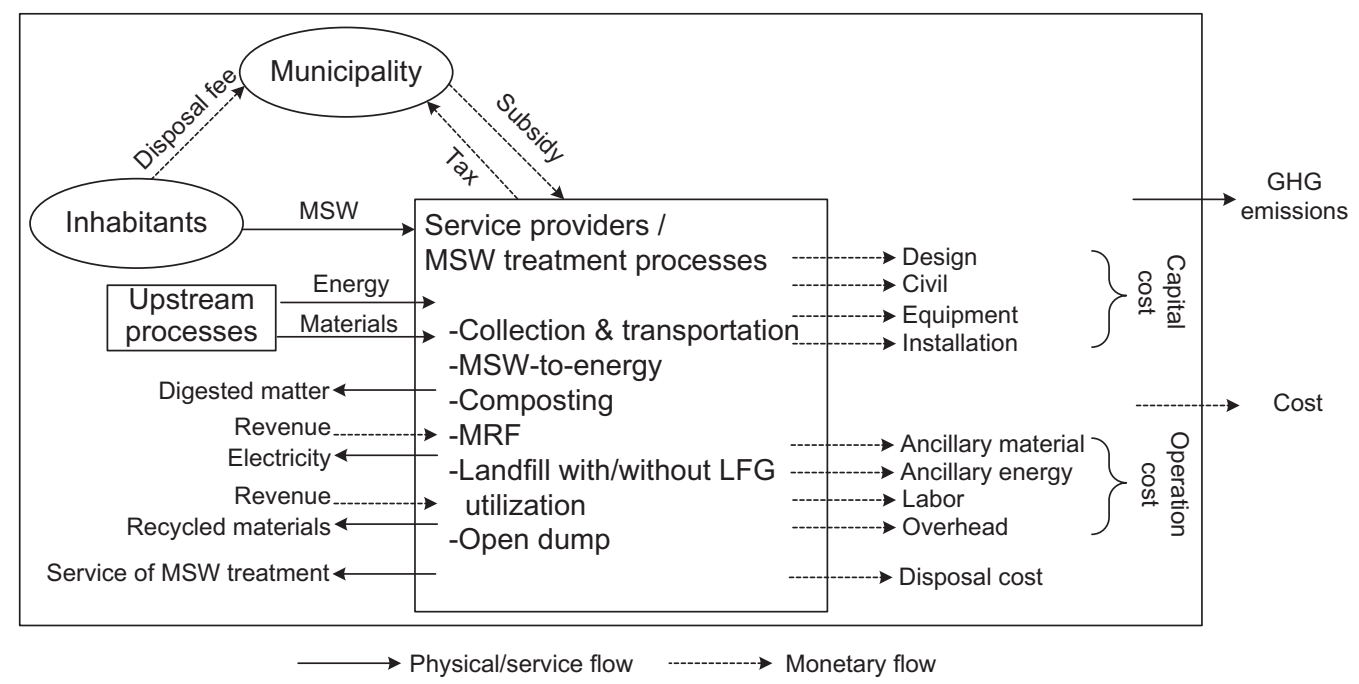

Fig. 1. System boundary for eco-efficiency analysis.

Table 4

Descriptions and data sources of processes studied.

\begin{tabular}{|c|c|c|c|}
\hline Process & Process descriptions & Data sources for LCA & Data sources for LCC \\
\hline $\begin{array}{l}\text { Landfill without LFG } \\
\text { utilization }\end{array}$ & $\begin{array}{l}2700 \text { ton/day, 10-year life span HDPE layer, LFG release } \\
\text { directly }\end{array}$ & $\begin{array}{l}\text { Tianjin Shuanggang landfill plant } \\
\text { (1999); Doka (2003) }\end{array}$ & $\begin{array}{l}\text { Tianjin Shuanggang landfill plant } \\
\text { (1999); assumptions }\end{array}$ \\
\hline $\begin{array}{l}\text { Landfill with LFG } \\
\text { utilization }\end{array}$ & $\begin{array}{l}\text { Similar to above, expect for LFG collection, purification and } \\
\text { electric generate system }\end{array}$ & $\begin{array}{l}\text { Tianjin Shuanggang landfill plant } \\
\text { (1999); Doka (2003) }\end{array}$ & $\begin{array}{l}\text { Tianjin Shuanggang landfill plant } \\
\text { (1999); Wang (1999) }\end{array}$ \\
\hline MSW-to-energy & $\begin{array}{l}400 \text { ton/day, } 20 \text {-year life span, grate incinerator with steam } \\
\text { turbine electric generator }\end{array}$ & $\begin{array}{l}\text { Tianjin MSW-to-energy plant (2006); } \\
\text { Doka (2003) }\end{array}$ & $\begin{array}{l}\text { Tianjin MSW-to-energy plant (2006); } \\
\text { assumptions }\end{array}$ \\
\hline MRF & 180 ton/day, 20-year life span & $\begin{array}{l}\text { Ecoinvent Database v2.0 (2009); } \\
\text { Arena et al. (2003) }\end{array}$ & Dubanowitz, 2000 \\
\hline Composting & 800 ton/day, 20-year life span, & Ecoinvent Database v2.0 (2009) & Yao et al. (2003); Xu (1999) \\
\hline Open dump & None & Emission factors from Doka (2003) & None \\
\hline $\begin{array}{l}\text { Collection and } \\
\text { transport }\end{array}$ & 5 ton diesel lorry, 10 -year life span & TCAEEDRI (2007); NBSC (2002) & TCAEEDRI (2007); assumptions \\
\hline $\begin{array}{l}\text { Processes in } \\
\text { background system }\end{array}$ & $\begin{array}{l}\text { Average technologies in China; Ecoinvent Database v2.0 } \\
\text { (2009) }\end{array}$ & $\begin{array}{l}\text { Di et al. (2007); Ecoinvent Database } \\
\text { v2.0 (2009) }\end{array}$ & $\begin{array}{l}\text { Tian et al. (2007); http:// } \\
\text { www.tjprice.gov.cn/ }\end{array}$ \\
\hline
\end{tabular}

operational costs and disposal costs, as shown in Fig. 1. The capital costs, which are presented as yearly average costs in the period of service life, are the sum of civil cost including land cost and construction cost, equipment cost, installation cost and design cost. The operational costs are the sum of material and energy costs, maintenance cost, labor cost, and overhead. The annual maintenance cost and the annual overhead are calculated as $2.5 \%$ of the civil and equipment costs and $2 \%$ of the capital costs, respectively. (Data provided by the engineer from Tianjin MSW-to-energy plant.) The disposal costs are the sum of costs for treating residual waste streams, such as incineration ashes and wastewater. At the end of the waste treatment facility's life cycle, the demolition cost is considered to be equal to the residual value, thus both of them can be neglected. The data sources of the cost inventory for each treatment process are listed in Table 4. For the purpose of comparison, the data of cost for China are converted into the constant market price at year 2000 in CNY, while those of cost for U.S. are also converted into the constant market price refer to year 2000 in dollar. The data are then converted into CNY in 2000 with purchasing power parity (PPPs) estimated by World Bank for the use of international comparison (UNCDB, 2008). Results of the cost inventory for each treatment process are listed Table 5 .

\subsubsection{Allocation}

As discussed in methodology section, economic allocation is selected as the allocation method in this study. Allocation factors of each unit process in both LCA and LCC analyses therefore are equal, which are calculated on the basis of market prices and quantities of the various products or services (Heijungs and Guinée, 2007; Zhao et al., 2009), as shown in Table 6. It is noted that the allocation factor of the digested matter is zero, because the digested matter from the composting process is usually given to farmers free of charge, according to the experience gained from European countries.

Table 5

Cost inventory results of each process studied.

\begin{tabular}{|c|c|c|c|c|}
\hline Process & Unit & Capital cost & Operational cost & Disposal cost \\
\hline Collection \& transport & CYN/ton.km & 0.33 & 2.29 & 0 \\
\hline Landfill without LFG utilization & CYN/ton & 34.45 & 10.76 & 1.5 \\
\hline Landfill with LFG utilization & CYN/ton & 46.11 & 12.01 & 1.5 \\
\hline MSW-to-energy & CYN/ton & 63.74 & 54.89 & 4.2 \\
\hline Composting & CYN/ton & 52.4 & 9.67 & 2.6 \\
\hline MRF & CYN/ton & 75.6 & 32.41 & 3 \\
\hline
\end{tabular}


Table 6

Allocation factors in economic allocation.

\begin{tabular}{|c|c|c|c|c|c|c|c|c|}
\hline \multirow[t]{2}{*}{ Unit process } & \multicolumn{8}{|l|}{ Function } \\
\hline & $\begin{array}{l}\text { Service of waste } \\
\text { treatment }\end{array}$ & $\begin{array}{l}\text { Recovered } \\
\text { electricity }\end{array}$ & $\begin{array}{l}\text { Digested } \\
\text { matter }\end{array}$ & $\begin{array}{l}\text { Recycled } \\
\text { paper }\end{array}$ & $\begin{array}{l}\text { Recycled } \\
\text { glass }\end{array}$ & $\begin{array}{l}\text { Recycled } \\
\text { metals }\end{array}$ & $\begin{array}{l}\text { Recycled } \\
\text { PE }\end{array}$ & $\begin{array}{l}\text { Recycled } \\
\text { PP }\end{array}$ \\
\hline MSW-to-energy & 0.62 & 0.38 & & & & & & \\
\hline $\begin{array}{l}\text { Landfill with LFG } \\
\text { utilization }\end{array}$ & 0.74 & 0.26 & & & & & & \\
\hline Composting & 1 & & 0 & & & & & \\
\hline Paper recycling & 0.11 & & & 0.89 & & & & \\
\hline Glass recycling & 0.16 & & & & 0.84 & & & \\
\hline Metals recycling & 0.06 & & & & & 0.94 & & \\
\hline Plastics recycling & 0.04 & & & & & & 0.69 & 0.27 \\
\hline
\end{tabular}

\subsubsection{Impact assessment and cost aggregation}

Focusing on GHG emissions mitigation, global warming is the only impact category for life cycle impact assessment in this study. The GHG emissions are characterized using global warming potentials for 100-year time horizon (GWP100), according to IPCC (2001). Since the steady-state cost model is used, all costs in three categories are allocated and aggregated at the annual level without discounting.

\subsection{Eco-efficiency analysis}

After conducting LCA and LCC, their results are compared and integrated. A contribution analysis is implemented to pinpoint the key issues with the highest contribution to global warming impact or cost impact. In this study, the contribution analysis is based on major stages of the MSW management system, distinguished as collection and transport; waste treatment processes (including landfill, MSW-to-energy, MRF and composting); materials and energy production; and infrastructure for waste treatment facility.

Related to the Kyoto Protocol, China, as a country of responsibility, aims to fulfill its commitments and has established strategic goals to reduce energy consumption per unit GDP, to raise the proportion of renewable energy in primary energy supply, and to increase the forest coverage rate, which consequently reduce GHG emissions. According to the China's National Climate Change Program (NDRC, 2007), the total GHG emissions in 2004, 6100 million ton $\mathrm{CO}_{2}$ eq., is set as the baseline, which is used for the global warming normalization in this study as well. The gross domestic product (GDP) of China is 21.2 trillion CNY in 2006, which is used for the cost normalization.

\subsection{Results and discussion}

\subsubsection{Contribution analysis}

Results from the contribution analysis on LCA and LCC are given in Fig. 2. The baseline scenario (S0) has been set at $100 \%$, and other scenarios are presented relative to it. S0 reflects the current MSW management situation in Tianjin. In terms of global warming impact, the landfill and MSW-to-energy stages contribute $68 \%$ and $26 \%$ to GHG emissions, respectively. The landfill process in S0 is not equipped with the LFG utilization or flaring system, which causes a high release of $\mathrm{CH}_{4}$ due to the organic waste degradation. The oxidation of fossil carbon in various waste fractions, e.g. plastics waste in Table 2, is the major source of GHG emissions from MSW-to-energy stage. In terms of cost impact, landfill stage in S0 contributes less than $5 \%$ of the total impact. In contrast, infrastructure and, collection and transport stages are major cost drivers, contributing in excess of $32 \%$ and $26 \%$, respectively.

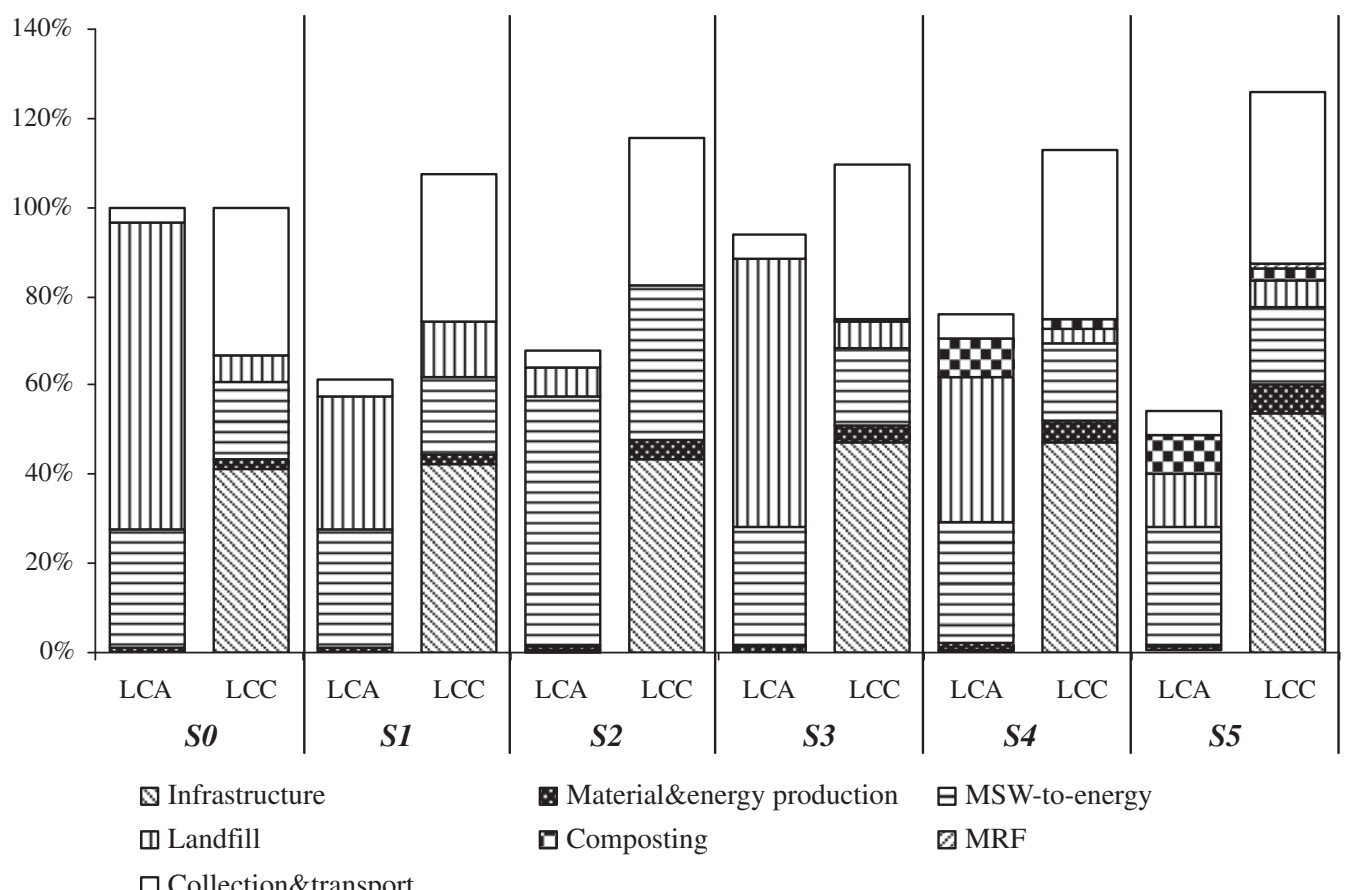

Fig. 2. Contribution analyses of environmental impact (LCA results) and economic impact (LCC results) of scenarios studied. 
The key issues arising from LCA and LCC contribution analyses, show no relation between the global warming impact and the cost impact. The results of other scenarios are quite similar to those of S0, as shown in Fig. 2. The robustness of this result has also been observed by other researchers (Hellweg et al., 2005). The proper explanation can be the fact that the large scale of the MSW management system, with regard to both capacity and geographical scope, causes a series of high monetary expenditures. Meanwhile, the environmental impacts of different MSW treatment processes are relatively higher than that of other processes. However, the situation may change in the future, as more stringent environmental standards of waste treatment technologies and new regulations on MSW source separation are established. The results of the contribution analysis also show potentials to improve the MSW management system from the environmental aspect or the economic aspect, by improving different key issues.

\subsubsection{Eco-efficiency analysis}

The $E / E_{\text {pairwise }, i j}$ indicator of any two scenarios, as defined in the methodology section, is depicted in Fig. 3. The LCA and LCC results of different scenarios are shown in Table 7 for reference. The baseline scenario (S0) reveals the least cost ( 79.9 million $\mathrm{CNY}$ ) but the most global warming impact (467.3 thousands ton $\mathrm{CO}_{2}$ eq.); while the integrated scenario (S5) is the most costly (98.9 million CNY) but least global warming impact (255.9 thousands ton $\mathrm{CO}_{2}$ eq.). Relative to S0, the recycling scenario (S3) costs more but its global warming impact is reduced slightly. The small benefit of GHG emissions mitigation (reduced by 6.1\% compared to S0) in S3 is the result of small shares of recyclable fractions in Tianjin's MSW, as shown in Table 2. The incineration scenario (S2) and the composing scenario (S4) show the significant GHG emissions mitigation at the economic cost. The cost of S2 (92.2 million CNY) is the second highest among scenarios, because the payments for infrastructure, operation and maintenance in the whole life cycle of MSW-to-energy plant are relatively high. For S4, its higher cost is partially influenced by the chosen economic allocation, which assumes the market price of the digested matter is zero

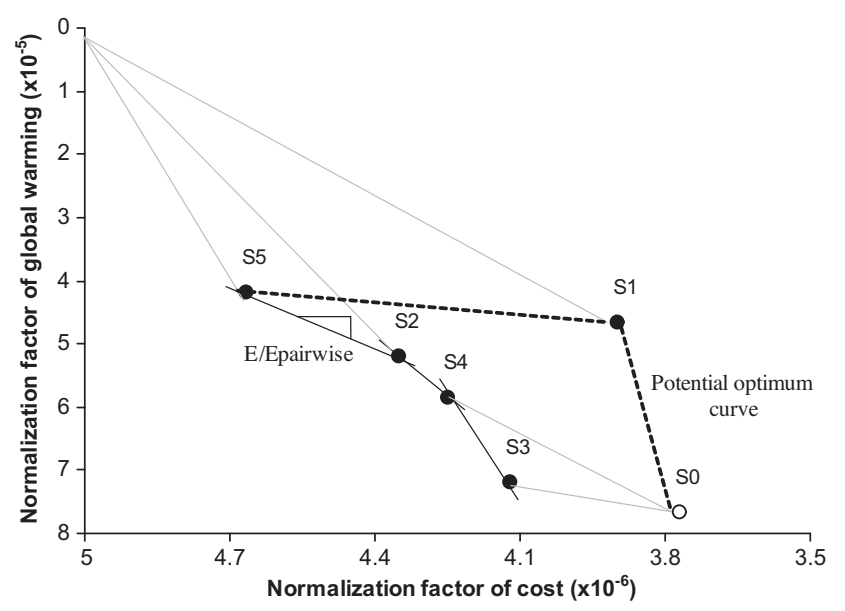

Fig. 3. Eco-efficiency (E/E) diagram of scenarios studied.

Table 7

LCA and LCC results of different scenarios.

\begin{tabular}{lllllll}
\hline & S0 & S1 & S2 & S3 & S4 & S5 \\
\hline $\begin{array}{l}\text { GHG emissions/thousands } \\
\text { ton } \mathrm{CO}_{2} \text { eq. }\end{array}$ & 467.3 & 285.6 & 316.6 & 438.5 & 357.2 & 255.9 \\
\begin{tabular}{l} 
Cost/million CNY \\
\hline
\end{tabular} & 79.9 & 82.7 & 92.2 & 87.3 & 90.0 & 98.9 \\
\hline
\end{tabular}

and total life cycle cost is taken by the service of kitchen waste composting. The LFG utilization scenario (S1) appears as a promising solution for GHG emissions mitigation of Tianjin's MSW management, performing similarly to S5 with regard to global warming impact and to SO with regard to cost impact.

If we remove all irrelevant scenarios, of which the global warming impact or the cost impact or both are higher than those of any other scenarios, the potential optimum scenarios remains, viz. S0, S1 and S5 in this case. Consequently, a set of the potential optimum scenarios may create a potential optimum curve, indicating the marginal eco-efficiency for the point shifting in other directions. The $E / E_{\text {pairwise, } i j}$ indicator (Eq. (5)) is applied to the present case to quantify the GHG emissions mitigation efficiency by a single figure. In both the $j$ th (in the first row) and the ith (in the first column) directions, all scenarios are listed in descending order of the global warming impact in Table 8 which covers all possible comparisons of the scenarios studied. The highest figure in each row is in bold type, referring to the strategy with the highest E/E for GHG emissions mitigation when shifting from the $i$ th scenario to the other scenarios. S1 is superior to all other scenarios except S5 in the second row. It is because that starting from S1, S5 is only one direction to reduce the global warming impact within the scope of this study. The last row in Table 6 is a special case, since the GHG emissions from S5 are the least; hence it makes no sense to shift from S5 to any other scenarios in this study. It can be concluded that S1 is the most eco-efficient scenario for GHG emissions mitigation, considering the Tianjin's MSW treatment technologies' levels and the limited financial supports. Compared to the baseline scenario, the second eco-efficient scenario is S2, followed by S4 and S5.

\subsubsection{Uncertainty}

The proposed E/E analysis for GHG emissions mitigation of MSW management system combines the environmental and economic assessments, towards the direction to sustainability. However, with respect to the scientific feasibility of the proposed $\mathrm{E} / \mathrm{E}$ analysis, uncertainties are a critical issue. A first aspect of uncertainty relates to the methodologies applied. Although we have deliberated on integrating LCA and LCC in a consistent way, the $\mathrm{E} / \mathrm{E}$ analysis is subject to many assumptions derived from either an integration procedure or the life cycle approach itself. For instance, the system boundaries of LCA and LCC are difficult to harmonize, and the uncertainties of those assumptions on cut-offs are not easily quantified. Furthermore, when we consider other environmental impact categories besides global warming, a crucial question with respect to weighting different impact categories arises, which is one of the inherent limitations of LCA. The second aspect of uncertainty relates to the assumptions on data and the quality of data. In the previous study (Zhao et al., 2009), we have discussed the uncertainties of the assumptions on LFG collection efficiency and recycle rate, both of which show high sensitivities on the GHG emissions from MSW management system. In the E/ E analysis, it is necessary to assess the effects of key variants on both environmental and economic impacts at the same time.

Table 8

Eco-efficiency (E/E) indicators for comparing scenarios.

\begin{tabular}{lllllll}
\hline$i$ & \multicolumn{2}{l}{ E/E pairwise $i j$} & & & \\
\cline { 2 - 7 }$j$ & $\mathrm{~S} 0$ & $\mathrm{~S} 1$ & $\mathrm{~S} 2$ & $\mathrm{~S} 3$ & $\mathrm{~S} 4$ & $\mathrm{~S} 5$ \\
\hline S0 & $\mathrm{n} / \mathrm{a}$ & $\mathbf{0 . 2 3}$ & 0.043 & 0.014 & 0.038 & 0.039 \\
S1 & n/a & n/a & n/a & n/a & n/a & $\mathbf{0 . 0 0 6}$ \\
S2 & n/a & $\rightarrow \infty$ & n/a & n/a & n/a & 0.032 \\
S3 & n/a & $\rightarrow \infty$ & 0.087 & n/a & 0.105 & 0.055 \\
S4 & n/a & $\rightarrow \infty$ & 0.065 & n/a & n/a & 0.04 \\
S5 & n/a & n/a & n/a & n/a & n/a & n/a \\
\hline
\end{tabular}


Increasing the recycle rate in $\mathrm{S} 5$, for example, could cause a decreased global warming impact and an increased cost impact. The competition between these two effects determines whether S5 moves towards the potential optimum curve or even whether the potential optimum curve changes. Summarizing, the uncertainties of major assumptions should be well documented, and be quantified by the sensitivity analysis.

\section{Conclusions}

This article has discussed the methodology of the E/E analysis, focusing on consistently integrating LCA and LCC. Five major methodological differences between LCA and LCC, potentially causing diversities or conflicts, have been examined and classified as time related differences or boundary related differences. Particularly, in MSW management system, key methodological choices have been made based on the comparison between LCA and LCC, including the steady-state LCC model, the economic allocation, and the discounting excluded. There are logical reasons and/or practical reasons to prefer these choices. In addition, the $E / E_{\text {pairwise,ij }}$ indicator for GHG emissions mitigation has been developed. In order to demonstrate the proposed E/E analysis, we have carried out the case study on MSW management in Tianjin.

The current patterns of Tianjin's waste management system and other five improved scenarios have been assessed. The key issues identified by the contribution analysis on LCA and LCC show no linear relationship between the global warming impact and the cost impact in MSW management system. The contribution results are useful to present the possible improvements from an environmental aspect or an economic aspect or both. The results from LCA and LCC have been normalized to Chinese national data, and represented in an E/E diagram. This graphical presentation of the $\mathrm{E} / \mathrm{E}$ analysis is transparent and helpful to understand the economic-environmental trade-offs involved in the scenarios. Furthermore, the potential optimum curve has been created by a set of the most promising scenarios, which can be used to analyze the marginal eco-efficiency. Because the E/E diagram cannot solve the trade-off problem, the indicator $E / E_{\text {pairwise }, i j}$ is calculated for specifying the rank of scenarios. The LFG utilization scenario is identified as the one with the highest E/E for GHG emissions mitigation, because of its significant reduction of the global warming impact and relatively small costs increase. Given the limited waste management practice and financial support in Tianjin, promising solution is installing LFG utilization systems for existing landfill plants or developing new landfill plant with LFG utilization systems. The factors, including the characteristics of MSW, technologies' levels, and the chosen methodologies, determine other scenarios are less attractive, from an $E / E$ perspective.

It is worth noting some limitations of this study. First, GHG emissions have been primarily concerned with environmental impact, as the E/E analysis for a specific environmental improvement measure. Other environmental impact categories ranging from ozone layer depletion to acidification and toxicity aspects, as well as political factors are also important in the waste management field and will alter both the absolute value and the $\mathrm{E} / \mathrm{E}$ indicator. Second, the scenarios constructed in this study do not incorporate dynamic factors. For instance, the changing amount and feature of MSW and improved or new waste treatment technologies will lead to different sets of scenarios, hence different $\mathrm{E} / \mathrm{E}$ analysis results. Introducing dynamic factors into the $\mathrm{E} / \mathrm{E}$ analysis makes it much more meaningful and much more complex (Huppes and Ishikawa, 2005b). Third, uncertainties related to methodological choices, data availabilities and data accuracy are necessary to be discussed in detail, in order to implement the $\mathrm{E} / \mathrm{E}$ analysis in a scientifically feasible way. There is, therefore, a need for a better and more comprehensive E/E analysis for assessing the economic-environmental reality of the waste management.

\section{Acknowledgements}

This work was supported by the Liaoning Ministry of Education through Technology \& Research Project (No. L2010185) and the Asia-Link project ProtEA (ProtEA=Human Resources Development for the Improvement and Protection of Environment in Asia), No. CN/ASIA-LINK (110-744).

\section{References}

Arena, U., Mastellone, M.L., Perugini, F., 2003. Life cycle assessment of a plastic packaging recycling system. Int. J. LCA 8, 217-224.

Bogner, J., Abdelrafie Ahmed, M., Diaz, C., Faaij, A., Gao, Q., Hashimoto, S., Mareckova, K., Pipatti, R., Zhang, T., 2007. Waste Management, In Climate Change: Mitigation. Cambridge University Press.

Cheng, H.F., Zhang, Y.G., Meng, A.H., Li, Q., 2007. Municipal solid waste fuelled power generation in China: a case study of waste-to-energy in Changchun city. Environ. Sci. Technol. 41, 7509-7515.

Di, X., Nie, Z., Yuan, B., Zuo, T., 2007. Life cycle inventory for electricity generation in China. Int. J. LCA 12, 217-224.

Doka, G., 2003. Life cycle inventories of waste treatment services. Ecoinvent report No.13. Swiss Center for Life Cycle for Life Cycle Inventories, Dübendorf.

Dubanowitz, A.J., 2000. Design of a materials recovery facility (MRF) for processing the recyclable materials of New York City's municipal solid waste. Master's thesis, Columbia University, New York.

Ecoinvent Database v2.0: <http://www.ecoinvent.org/>. Accessed May 2009.

Eshet, T., Ayalon, O., Shechter, M., 2005. A critical review of economic valuation studies of externalities from incineration and land filling. Waste Manage. Res. 23, 487-504.

Guinée, J.B., Gorrée, M., Heijungs, R., Huppes, G., Kleijn, R., de Konin, A., van Oers, L., Wegener Sleeswijk, A., Suh, S., Udo de Haes, H.A., de Bruijn, H., van Duin, R., Huijbregts, M.A.J., 2002. Handbook on life cycle assessment. Springer, The Netherlands.

Heijungs, R., Guinée, J.B., 2007. Allocation and 'what-if' scenarios in life cycle assessment of waste management systems. Waste Manage. 27 (8), 997-1005.

Hellweg, S., Doka, G., Finnveden, G., Hugerbuhler, K., 2005. Assessing the ecoefficiency of end-of-pipe technologies with the environmental cost efficiency indicator: a case study of solid waste management. J. Ind. Ecol. 9 (4), 189-203.

Huppes, G., Ishikawa, M., 2005a. A framework for quantified eco-efficiency analysis. J. Ind. Ecol. 9 (4), 25-41.

Huppes, G., Ishikawa, M., 2005b. Why eco-efficiency? J. Ind. Ecol. 9 (4), 2-5.

Huppes, G., van Rooijen, M., Kleijn, R., Heijungs, R., de Koning, A., van Oers, L., 2004. Life Cycle Costing and the Environment. CML Report. Leiden University, Leiden.

Ibenholt, K., Lindhjem, H., 2003. Costs and benefits of recycling liquid board containers. J Consum Policy 26, 301-325.

Indrianti, N., Matsuoka, S., Muraki, M., 2007. A strategic policy model for promoting secondary materials use. In: Huppes, G., Ishikawa, M. (Eds.), Quantified Ecoefficiency. Springer, The Netherlands.

IPCC (Intergovernmental Panel on Climate Change), 2001. Climate Change 2001: The scientific basis. Contribution of working group I to the third assessment report of the Intergovernmental Panel on Climate Change. Cambridge University Press, Cambridge, United Kingdom and New York, NY, USA.

NBSC (National Bureau of Statistics of China), 2002. China energy statistical yearbook 2000-2002. China Statistics Press, Beijing.

NDRC (National development and reform commission), 2007. China's national climate change program. Beijing.

RDC and PIRA, 2003. Evaluation of costs and benefits for the achievement of reuse and recycling targets for the different packaging materials in the frame of the packaging and packaging waste directive 94/62/EC. European Commission.

Reich, M.C., 2005. Economic assessment of municipal waste management systems, case studies using a combination of life cycle assessment (LCA) and life cycle costing (LCC). J. Clean Prod. 13 (3), 253-263.

TBS (Tianjin Bureau of Statistics), 2007. Tianjin statistical yearbook 2006. China Statistics Press, Beijing.

TCAEEDRI (Tianjin City Appearance Environmental Engineering Design and Research Institute), 2007. Investigation on municipal solid waste in Tianjin 2006. Tianjin.

Thorneloe, S.A., Weitz, K., Jambeck, J., 2007. Application of the US decision support tool for materials and waste management. Waste Manage. 27, 1006-1020.

Tian, B.G., Si, J.T., Zhao, Y., Wang, H.T., Hao, J.M., 2007. Approach of technical decision-making by element flow analysis and Monte-Carlo simulation of municipal solid waste stream. J. Environ. Sci. 19, 633-640.

Tianjin MSW-to-energy plant, 2006. Annual company report. Tianjin.

Tianjin Shuanggang landfill plant, 1999. Landfill plant design and management report. Tianjin. 
UNCDB (United Nations Common Database), 2008. United Nations Statistic Division. Available from: <http://unstats.un.org/unsd/cdb_discontinued/ cdb_discontinued.asp>.

Wang, D.X., 1999. Hangzhou Tianziling landfill gas generator. Environ. Sanit. Eng. 7 (4), 151-153 (in Chinese).

WBCSD (World Business Council for Sustainable Devlopment), 2000. Measuring eco-efficiency. A guide to reporting company performance. Geneva.

$\mathrm{Xu}, \mathrm{C} ., 1999$. Ecological engineering for MSW treatment and utilization. Ph.D. thesis Chinese Academy of Sciences. Beijing, China.

Yao, H., Wu, W., Liu, J.M., Gu, Z.M., 2003. On advantages and disadvantages of solid waste treatment technology. Chin. J. Rock Mech. Eng. 22 (10), 1756-1759 (in Chinese).

Zhao, W., van der Voet, E., Zhang, Y.F., Huppes, G., 2009. Life cycle assessment of municipal solid waste management with regard to greenhouse gas emissions: case study of Tianjin, China. Sci. Total Environ. 407, 1517-1526.

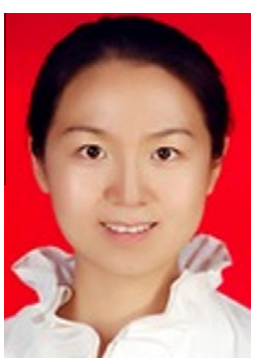

Wei Zhao is a lecturer at the College of Civil Engineering \& Architecture at Liaoning University of Technology in Jinzhou, China. Her main research area is integrated assessment of sustainable waste management.

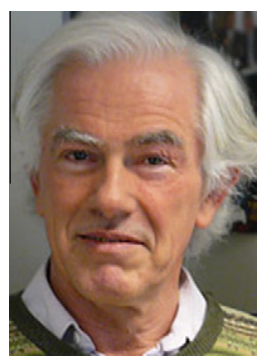

Gjalt Huppes is head of the Industrial Ecology Department and an associate professor of environmental system sciences at the Institute of Environmental Sciences $(\mathrm{CML})$ at Leiden University in Leiden, the Netherlands.

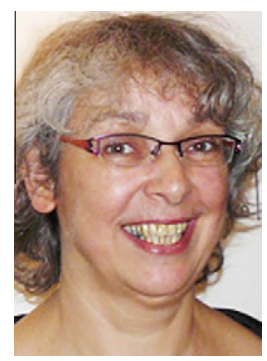

Ester van der Voet is an associate professor of environmental system sciences at the Institute of Environmental Sciences (CML) at Leiden University in Leiden, the Netherlands. 